ISSN 2411-9563 (Print) ISSN 2312-8429 (Online)
European Journal of Social Sciences Education and Research
September-December 2014

Volume 1, Issue 2

\title{
MARITIME ENGLISH LANGUAGE RESTRICTEDNESS
}

\author{
Sanela Kovacevic \\ sanelap@ac.me
}

\section{Abstract}

\begin{abstract}
Maritime English is a specific register. Therefore, it requires a specific treatment. This paper implies the restricted aspect of a complex system such as English for specific purpose in the nautical education and profession. The sophisticated system of the maritime English makes it a plain instrument of communication. The opposite "tides" govern the system: creative and economical tendency. The creative side of the maritime language is evident in the forming of new words and meanings, combining of existing units, various metaphors, etc. We have tried to look into certain subregisters within Standard Marine Communication Phrases (SMCP) by pointing to the main characteristics. Seaspeak is a vital instrument of communication on board a ship. The importance of English language has always been emphasized, especially the importance of the standardized maritime phrases used in vessel-to-vessel vessel-to-port communication. By trying to encode the Maritime English world, we will look into the structure of Maritime English communication terms and phrases. However, we cannot make artificial borders between Maritime and General English. These two registers intertwine and it is impossible to eliminate Maritime English from General English and vice versa. As far as restricted aspect of Maritime English is concerned, Standard Marine Communication Phrases are used in both ship-to-ship and ship-to-shore communication.
\end{abstract}

Keywords: SMCP, linguistic, restricted language, lexicology, maritime terms, discourse analysis, pragmatics, seaspeak, specific purpose, ship, sail, rudder, derrick, VHF-equipment, needs analysis.

\section{Introduction}

The Standard Marine Communication Phrases (SMCP) is a set of key phrases in the English language (which is the internationally recognized language of the sea), supported by the international community for use at sea and developed by the IMO.They aim to explain:1) external communication phrases - ship to ship \& ship to shore communication; 2) on-board communication phrases - communication within the ship. The SMCP were adopted by the 22nd Assembly of the IMO in November 2001 in a resolution which also promoted the wide circulation of the SMCP to all prospective users and all maritime education authorities. The SMCP includes phrases which have been developed to cover the most important safety-related fields of verbal shore-to-ship (and vice-versa), ship-to-ship and on-board communications. The aim is to reduce the problem of language barriers at sea and avoid misunderstandings which can cause accidents.

As navigational and safety communications from ship to shore and vice versa, ship to ship , and on board ships must be precise, simple and unambiguous, so as to avoid confusion and error, there is a need to standardize the language used. This is of particular importance in the light of the increasing number of internationally trading vessels with crews speaking many different languages since problems of communication may cause misunderstandings leading to dangers to the vessel, the people on board and the environment. in 1973 the IMO Maritime Safety Committee agreed at its twenty-seventh session that, where language difficulties arise, a common language should be used for navigational purposes and that language should be English. in consequence the SWNV was developed, adopted in 1977 and amended in 1985. in 1992 the IMO Maritime Safety Committee at its sixtieth session instructed the IMO Sub-Committee on Safety of Navigation to develop a more comprehensive standardized safety language than the SMNV, 1985, taking into account the changing conditions in modern seafaring and covering all major safety-related verbal communications. At its sixty-eighth session in 1997 the IMO Maritime Safety Committee adopted the Draft Standard Marine Communication Phrases (SMCP) developed by the IMO Sub Committee on Safety of Navigation. The Draft SMCP, following international trials, was amended at the forty-sixth session of this Sub-Committee and final consideration given at the IMO Maritime Safety Committee. Under the International Convention on Standards of Training, Certification and Watch-keeping for Seafarers, 1978, as revised 1995, the ability to understand and use the SMCP is required for the certification of officers in charge of a navigational watch on ships of 500 gross tonnage or more. Committee at its session in the light of remarks received by the Organization.

\subsection{Position of the SMCP in maritime practice}

The Standard Marine Communication Phrases (SMCP) has been compiled:

- to assist in the greater safety of navigation and of the conduct of the ship, 
- to standardize the language used in communication for navigation at sea, in port-approaches, in waterways, harbours and on board vessels with multilingual crews, and

- to assist maritime training institutions in meeting the objectives mentioned above.

These phrases are not intended to supplant or contradict the International Regulations for Preventing Collisions at Sea, 1972 or special local rules or recommendations made by IMO concerning ships' routeing, neither are they intended to supersede the International Code of Signals, and when applied in ship's external communication this has to be done in strict compliance with the relevant radiotelephone procedures as set out in the ITU Radio Regulations. Furthermore, the SMCP, as a collection of individual phrases, should not be regarded as any kind of technical manual providing operational instructions.

The SMCP meets the requirements of the STCW Convention, 1978, as revised, and of the SOLAS Convention, 1974, as revised, regarding verbal communications; moreover, the phrases cover the relevant communication safety aspects laid down in these Conventions.

Use of the SMCP should be made as often as possible in preference to other wording of similar meaning; as a minimum requirement users should adhere as closely as possible to their wording in relevant situations. in this way they are intended to become an acceptable safety language, using English for the verbal interchange of intelligence among individuals of all maritime nations on the many and varied occasions when precise meanings and translations are in doubt, increasingly evident under modern conditions at sea. The accompanying $\mathrm{CD} /$ Cassette is designed to familiarize users with the pronunciation of the phrases.

\subsection{Organization of the SMCP}

The SMCP is divided into External Communication Phrases and On-board Communication Phrases as far as its application is concerned, and into PART A and PART B as to its status within the framework of the STCW, 1978, as revised. PART A covers phrases applicable in external communications and which may thus be regarded as the replacement of the Standard Marine Navigational Vocabulary, 1985, which is requested to be used and understood by the STCW Code, 1995, Table AII/I. This part was enriched by essential phrases concerning shiphandling and safety of navigation to be used in on-board communications, particularly when the Pilot is on the bridge, as required by Regulation 14(4), Chapter V, SOLAS 1974,as revised.

PART B calls attention to other on-board standard safety-related phrases which, supplementary to PART A, may also be regarded useful for Maritime English instruction.

\subsection{Position of the SMCP in Maritime Education and Training}

The SMCP does not intend to provide a comprehensive Maritime English syllabus which is expected to cover a far wider range of language skills to be achieved in the fields of vocabulary, grammar, discourse abilities, etc., than the SMCP could ever manage... However, PART A in particular, should be an indispensable part of any curriculum which is designed to meet the corresponding requirements of the STCW Convention, 1978, as revised. in addition, PART B offers a rich choice of situations covered by phrases well suited to meet the communication requirements of the STCW Convention, 1978, as revised, which are implicitly expected to be satisfied by mariners.

The SMCP should be taught and learnt selectively, according to the users' specific needs rather than completely. The respective instruction should be based on practice in the maritime environment and be implemented through appropriate modern language teaching methods.

\subsection{Basic communicative features}

The SMCP builds on a basic knowledge of the English language. It was drafted on purpose in a simplified version of Maritime English to reduce grammatical, lexical and idiomatic varieties to a tolerable minimum, using standardized structures for the sake of its function aspects, i.e. diminishing misunderstanding in safety related verbal communications, thereby endeavouring to reflect present Maritime English language usage on board vessels and in ship-to-shore/ship-toship communications. This means, in phrases offered for use in emergency and other situations developing under considerable pressure of time or psychological stress as wells as in navigational warnings, a block language was applied 
which sparingly uses, or frequently omits, the function words the, a/an, is/are as done in seafaring practice. Users, however, may be flexible in this respect.

Further communicative features may be summarized as follows:

avoiding synonyms

avoiding contracted forms

· providing fully worded answers to "yes/no"-questions and basic alternative answers to sentence questions

- providing one phrase for one event, and

- structuring the corresponding phrases after the principle: identical invariable plus variable.

\subsection{Typographical conventions}

( ) brackets indicate that the part of the message enclosed within the brackets may be added where relevant;

I oblique strokes indicate that the items on either side of the stroke are alternatives;

... dots indicate that the relevant information is to be filled in where the dots occur;

(italic letters) indicate the kind of information requested;

$\sim$ tildes stand for the invariable part of an aforementioned standard phrase which is followed by a variable addendum

\section{LINGUISTIC RESTRICTEDNESS AND ACCURACY IN SAFETY-RELATED COMMUNICATION}

\subsection{Procedure}

When it is necessary to indicate that the SMCP are to be used, the following message may be sent:

"Please use Standard Marine Communication Phrases."

"I will use Standard Marine Communication Phrases."

\subsection{Spelling}

\subsubsection{Spelling of letters}

When spelling is necessary, only the following spelling table should be used:

Letter Code Letter Code

A Alfa N November

B Bravo O Oscar

C Charlie P Papa

$D$ Delta $Q$ Quebec

E Echo R Romeo

F Foxtrot S Sierra

G Golf T Tango

H Hotel U Uniform

I India V Victor

J Juliet W Whisky

K Kilo XX-ray

L Lima Y Yankee 
M Mike Z Zulu

\subsection{Responses}

\subsection{1}

When the answer to a question is in the affirmative, say:

"Yes, .... " - followed by the appropriate phrase in full.

\subsection{2}

When the answer to a question is in the negative, say:

"No, ..." - followed by the appropriate phrase in full.

\subsection{3}

When the information requested is not immediately available, say:

"Stand by" - followed by the time interval within which the information will be available.

\subsection{4}

When the information requested cannot be obtained, say:

"No information."

\subsection{5}

When an INSTRUCTION (e.g. by a VTS-Station, Naval vessel or other fully authorized personnel ) or an ADVICE is given, respond if in the affirmative:

"I will/can ... " - followed by the instruction or advice in full; and,

if in the negative, respond:

"I will not/cannot ... " - followed by the instruction or advice in full.

Example: "ADVICE. Do not overtake the vessel North of you."

Respond: "I will not overtake the vessel North of me."

\subsection{6}

Responses to orders and answers to questions of special importance both in external and onboard communication are given in wording in the phrases concerned.

\subsection{Distress, urgency and safety signals}

\subsection{1}

MAYDAY to be used to announce a distress message

\subsection{2}

PAN - PAN to be used to announce an urgency message 
2.4.3 SĖCURITÈ to be used to announce a safety message

\subsection{Standard organizational phrases}

\subsection{1}

"How do you read (me)?"

\subsubsection{1}

"I read you ...

bad/one with signal strength one (i.e. barely perceptible)

poor/two with signal strength two (i.e. weak)

fair/three with signal strength three (i.e. fairly good)

good/four with signal strength four (i.e. good)

excellent/five with signal strength five (i.e. very good)

\section{5 .2}

When it is advisable to remain on a VHF Channel / frequency say:

"Stand by on VHF Channel ... / frequency ... "

\subsubsection{1}

When it is accepted to remain on the VHF channel / frequency indicated, say:

"Standing by on VHF Channel ... / frequency ... "

\subsection{3}

When it is advisable to change to another VHF Channel / frequency, say:

"Advise (you) change to VHF Channel ... / frequency ... ."

"Advise(you) try VHF Channel .. / frequency... ."

\subsubsection{1}

When the changing of a VHF Channel / frequency is accepted, say:

"Changing to VHF Channel ... / frequency ... ."

\subsection{Corrections}

When a mistake is made in a message, say:

"Mistake ..." - followed by the word:

"Correction ... " plus the corrected part of the message.

Example: "My present speed is 14 knots - mistake.

Correction, my present speed is 12 , one-two, knots

\subsection{Readiness}

"I am / I am not ready to receive your message" 


\subsection{Repetition}

\subsection{1}

If any part of the message are considered sufficiently important to need safeguarding, say:

"Repeat ..." - followed by the corresponding part of the message.

Example: "My draft is 12.6 repeat one-two decimal 6 metres."

"Do not overtake - repeat - do not overtake."

\section{8 .2}

When a message is not properly heard, say:

"Say again (please)."

\subsection{Numbers}

A few digits and numbers have a modified pronunciation compared to general English:

number spelling pronunciation

0 zero ZEERO

1 one WUN

2 two TOO

3 three TREE

4 four FOWER

5 five FIFE

\section{6 six SIX}

\section{7 seven SEVEN}

8 eight AIT

9 nine NINER

1000 thousand TOUSAND

2.9.1.

All numbers except whole thousands should be transmitted by pronouncing each

digit separately: "Wun-fife-zero" for 150

\subsection{2.}

Whole thousands should be transmitted by pronouncing each digit in the number of thousands followed by the word TOUSAND

\subsection{3}

Numbers continuing a decimal point should be transmitted as above, with the decimal point indicated by the word DECIMAL.

"Two decimal five" or Two point fivefor 2.5

Note: Attention! When rudder angles e.g. in wheel orders are given, say: 


\section{8 becomes ONE FIVE SIX DECIMAL EIGHT}

\subsection{Positions}

\subsection{0 .1}

When latitude and longitude are used, these shall be expressed in degrees and minutes (and decimals of a minute if necessary), North or South of the Equator and East or West of Greenwich.

Example:

"WARNING. Dangerous wreck in position 15 degrees 34 minutes North

061 degrees 29 minutes West."

\subsection{0 .2}

When the position is related to a mark, the mark shall be a well-defined charted object. The bearing shall be in the 360 degrees notation from true north and shall be that of the position FROM the mark.

\section{Example:}

"Your position bearing 137 degrees from Big Head lighthouse distance 2.4 nautical miles."

\subsection{Bearings}

The bearing of the mark or vessel concerned, is the bearing in the 360 degree notation from north (true north unless otherwise stated), except in the case of relative bearings.

Bearings may be either FROM the mark or FROM the vessel.

Examples: "Pilot boat is bearing 215 degrees from you."

Note: Vessels reporting their position should always quote their bearing FROM the mark.

\subsection{1}

\section{Relative bearings}

Relative bearings can be expressed in degrees relative to the vessel's head. Morefrequently this is in relation to the port or starboard bow.

Example:

"Buoy 030 degrees on your port bow."

(Relative D/F bearings are more commonly expressed in the 360 degree notation.)

\subsection{Courses}

Always to be expressed in 360 degree notation from north (true north unless otherwise stated). Whether this is to TO or FROM a mark can be stated. 


\subsection{Distances}

Preferably to be expressed in nautical miles or cables (tenths of a mile) otherwise in

kilometres or metres, the unit always to be stated.

\subsection{Speed}

To be expressed in knots:without further notation meaning speed through the water; or,"ground speed" meaning speed over the ground.

\subsection{Times}

Times should be expressed in the 24 hour UTC notation; if local time will be used in ports or harbours it should clearly be stated.

\subsection{Geographical names}

Place names used should be those on the chart or in Sailing Directions in use.

Should these not be understood, latitude and longitude should be given.

\subsection{Ambiguous words}

Some words in English have meanings depending on the context in which they appear.

Misunderstandings frequently occur, especially in VTS communications, and have produced accidents. Such words are:

\subsection{7 .1}

The Conditionals "May", "Might", "Should" and "Could".

May

Do not say: "May I enter the fairway?"

Say: "QUESTION. Do I have permission to enter the fairway?"

Do not say: "You may enter the fairway."

Say: "ANSWER. You have permission to enter the fairway."

Might

Do not say: "I might enter the fairway."

Say: "INTENTION. I will enter the fairway."

Should

Do not say: "You should anchor in anchorage B 3."

Say: "ADVICE. Anchor in anchorage B 3."

Could

Do not say: "You could be running into danger."

Say: "WARNING. You are running into danger."

The word "Can" either describes the possibility or the capability of doing something.In the SMCP the situations where phrases using the word "Can" appear make it clear whether a possibility is referred to. in an ambiguous context, however, say, for example: 
QUESTION:"Do I have permission to use the shallow draft fairway at this time?",

Do not say: "Can I use the shallow draft fairway at this time?", if you ask for a permission. (The same applies to the word "May")

\section{CONCLUSION}

We can conclude that maritime English is a restricted language which is characterized by a great many specific features on the phonological, morphological, lexical and syntaxical level. These particularities are the most obvious on the lexical level, for it implies maritime terms. This level is also under the greatest influence of the real world, that is the world outside language sphere.

Since the maritime language is further subdivided into registers and subregisters, we can make a distinction between maritime language and maritime languages. The complexity of the nautical register makes learning, that is acquisition very difficult. One should firstly learn maritime terms in his own mother tongue and then move into the maritime English world.

\section{References:}

[1] Lakić, I., (1997): "ESP at the End of the Century: Genre analysis", symposium, Language and Literature at the end of XX Century, Collection of Papers, Podgorica.

[2] Kluijven, P.C. van, (2003): The International Maritime Language Programme. An English Course for students at Maritime Colleges and for on-board training, Alk \& Heijnen Publishers, Alkmaar, The Netherlands.

[3] Thompson, S. (1994): "Frameworks and contexts: a genre-based approach to analysing lecture introductions", English for Specific Purposes, Vol.13.

[4] Thornbury, S., (2002): How to Teach Vocabulary, Essex, Pearson Education Limited.

[5] Widdowson, H.G., (1998): "Communication and Community the Pragmatics of ESP", English for Specific Purposes, Vol. 17, No 1 